\title{
Inhibit Scale
}

National Cancer Institute

\section{Source}

National Cancer Institute. Inhibit Scale. NCI Thesaurus. Code C121463.

A rating scale included in the Behavior Rating Inventory of Executive Function that

measures the ability of an individual to control impulses (inhibitory control) and to stop engaging in a behavior at the appropriate time. 